\title{
Pérdida y rescate de los derechos económicos, políticos y culturales de los pueblos originarios en El Salvador, en relación con la declaración de Naciones Unidas sobre los derechos de los pueblos indígenas
}

\author{
Loss and rescue of the economic, political and cultural rights \\ of the indigenous peoples in El Salvador in relation to the United Nations \\ declaration on their rights
}

URI: http://hdl.handle.net/11298/457

Marcelino Rodolfo-Rojas Salvador Alexander Ramos-Hernández ${ }^{2}$ Katherine Guadalupe Mejía-Martínez ${ }^{3}$ José Antonio Cañada-Hernández ${ }^{4}$

Universidad Tecnológica de El Salvador marcelino.rojas@utec.edu.sv

DOI: http://dx.doi.org/10.5377/entorno.v0i65.6054

\section{Resumen}

El presente artículo es el resultado final de un proyecto de investigación respecto de la pérdida y rescate de los derechos económicos, políticos y culturales de los pueblos originarios en El Salvador, así como la aplicación de sus derechos humanos en la actualidad, según la Declaración de Naciones Unidas sobre los derechos de

\section{Abstract}

This article is the result of a research project related to the loss and rescue of the economic, political and cultural rights of the indigenous peoples in El Salvador; it is also related to the application of their human rights at present, according to the United Nations Declaration on the human rights of indigenous peoples, in contrast with

\footnotetext{
${ }^{1}$ Docente de Filosofía de la Escuela en Antropología de la Universidad Tecnológica de El Salvador

${ }^{2}$ Estudiante de la licenciatura en antropología de la Universidad Tecnológica de El Salvador.

${ }^{3}$ Estudiante de la licenciatura en antropología de la Universidad Tecnológica de El Salvador.

${ }^{4}$ Estudiante de la licenciatura en antropología de la Universidad Tecnológica de El Salvador.
} 
los pueblos indígenas, contrastando con la condición de vida de los indígenas salvadoreños. En síntesis, la tesis principal es que la intervención del Estado salvadoreño es fundamental para el reconocimiento de los derechos de los pueblos originarios relativos a la calidad de vida económica, política y cultural.

Con base en los resultados, la actual situación económica, política y cultural que viven los diferentes pueblos originarios en El Salvador es difícil, esto a pesar de recibir una pequeña ayuda económica por parte del Gobierno. Sin embargo, esta ayuda no es suficiente para sostener los necesarios programas de reactivación de la economía, política y cultura. Políticamente tienen voz y voto debido a que son salvadoreños por nacimiento, sin embargo, como pueblos indígenas no tienen la capacidad de expresarse socialmente; son pueblos que tratan de sobrevivir al paso de los años; y lo máximo que está realizando el Estado es la innovación de métodos para atraer el turismo. Aun así, dichos pueblos se esfuerzan constantemente contra muchas más situaciones que ponen en riesgo su existencia. El problema radica en la falta de educación sobre sus derechos humanos. Este desconocimiento provoca que los dirigentes indígenas conozcan qué lugar ocupan en la estructura social del país y cuáles son sus posibilidades de participación económica, política y cultural; y esta falta de conocimiento, organización y participación es aprovechada por los sectores públicos y privados para dejarlos en el olvido.

Entre las principales causas que provocan la falta de cumplimiento, por parte del Estado salvadoreño, de los derechos humanos de los pueblos originarios está el poco conocimiento que han adquirido estos acerca de los derechos humanos que las leyes nacionales e internacionales establecen, y que pueden aplicar a su favor.

Por ende, se propone realizar capacitaciones en relación con los derechos de los pueblos originarios y de los derechos establecidos en la Constitución de la República de El Salvador, y hacer convenios con medios de comunicación para que presenten la forma de vida their life conditions in El Salvador. In synthesis, the main thesis is that the intervention of the Salvadorean State is fundamental for the acknowledgement of the rights of the indigenous peoples in relation to their quality of economic, political and cultural life.

Based on the findings, the current economic, political and cultural situation experienced by the different indigenous peoples in El Salvador is harsh, in spite of receiving a small economic assistance from the government. However, this assistance is not enough to sustain the necessary programs for the reactivating of their economy, politics and culture. Politically speaking, they have a voice and a right to vote since they are Salvadorean citizens by birth, nonetheless, they lack the capacity to express themselves socially as indigenous peoples; these are peoples who try to survive the passing of the years. The maximum effort by the State is the innovation of methods to attract tourism. Even so, said peoples are constantly making an effort against many more situations that put their existence at risk. The problem resides in the lack of education on their human rights. This lack of knowledge causes that the indigenous leaders know what place they occupy in the social structure of the country and what the possibilities for their economic, political and cultural participation are. This same lack of knowledge, organization and participation is taken advantage of by the public and private sectors to leave them in oblivion.

The little knowledge acquired about the human rights that both national and international laws establish and that they can apply to their benefit, are among the main causes for the lack of compliance by the Salvadorean State on the human rights of the indigenous peoples.

Therefore, a series of trainings in relation to the human rights of indigenous peoples and the rights established in the Constitution of the Republic has been proposed. Also, there is a proposal for the establishment of agreements with the mass media in order to show the lifestyle of the indigenous population and, based on 
de la población indígena, y, a partir de esto, gestionar proyectos de rescate y valoración de esos derechos.

\section{Palabras clave}

El Salvador - Violación de los derechos humanos. Derechos humanos - El Salvador. Antropología política - El Salvador. Indígenas de El Salvador - legislación. Derechos civiles - El Salvador. Indígenas de El Salvador Aspectos sociales. this, to generate projects for the rescue and valuation of said rights.

\section{Keywords}

El Salvador-Human rights violation. Human rights-El Salvador. Political anthropology-El Salvador. Indigenous peoples-Legislation. Civil rights-El Salvador. Indigenous peoples of El Salvador-Social aspects.

\section{Introducción}

En El Salvador, a simple vista podemos determinar que se ha formado una nación con poco interés hacia la cultura de los pueblos originarios. Sin embargo, existe un pequeño porcentaje que practica estos valores culturales y reconoce su importancia, pese a eso es una minoría; y se sabe que una minoría difícilmente hace cambios, por lo que se vuelve necesaria la intervención del Estado salvadoreño y de otras instituciones nacionales e internacionales.

Cada uno de los temas de coyuntura y agenda nacional evidencian que no existe una importancia significativa respecto a esta clase de temas indígenas, y no existen políticas suficientes para el beneficio de la cultura de los pueblos originarios salvadoreños. Al contrario, las instituciones del Estado históricamente han mantenido alejadas a estos del poder político y de la riqueza económica.

La problemática de pérdida y de rescate de los derechos económicos, políticos y culturales de los pueblos originarios en El Salvador es el punto de enfoque que precisamente se desarrolló en esta investigación. Se plantearon preguntas como ¿por qué el estado salvadoreño no se encuentra reconociendo los derechos de los pueblos originarios? ¿Qué consecuencias se siguen de que esta problemática no tenga relevancia? ¿En que podría repercutir que, con el paso de los años, no estén siendo reconocidos los derechos de los pueblos originarios? ¿Qué acciones se pueden tomar, a fin de motivar y cultivar el interés por la cultura e identidad étnica en las nuevas generaciones? ¿Qué medidas se pueden tomar en la población, en beneficio de las comunidades de pueblos originarios aún existentes?

\section{Algunas expectativas del trabajo de investigación}

Con la investigación se pretendió alcanzar nuevos conocimientos sobre los pueblos originarios. Y qué mejor conocimiento que buscar el origen y estar al tanto de la actualidad y realidad en la cual habitan estos pueblos. Las expectativas fueron muy altas, intentando conocer más acerca del cumplimiento, o no, de los derechos de los pueblos originarios en El Salvador. Además formular y delimitar la problemática, las causas que ocasionan dicha problemática que se investigaría, en concreto, cuáles son los obstáculos para que los pueblos originarios estén siendo olvidados, cuando de acuerdo con la Declaración de Naciones Unidas sobre los Derechos de los Pueblos Indígenas no debería de ser así. También se esperaba conocer las diferentes consecuencias que tal olvido de estos derechos está ocasionado, tanto a los pueblos originarios como a la sociedad salvadoreña. Y, finalmente, con la investigación se buscó obtener diversas alternativas, que con nuevos estudios se conviertan en propuestas de solución para estos pueblos originarios. Con esta investigación se está seguro de que contribuirá a volver a escribir la historia de la identidad étnica de El Salvador. Y, probablemente, conseguir que nuestros pueblos originarios sean dignos de admirar.

También se espera el rescate de las diferentes costumbres y tradiciones de los pueblos originarios de El Salvador, obtener un mayor conocimiento de las raíces de la cultura actual de los salvadoreños, profundizar más en el conocimiento y respeto a los derechos humanos de los pueblos originarios, conocer sobre la importancia que le da el Estado a los hoy existentes en El Salvador, y tratar de encontrar una solución viable para hacer valer sus derechos. 
A su vez, se espera acercarse más a estos pueblos y rescatar parte de las costumbres y tradiciones de los antepasados salvadoreños, así como poder contribuir a su desarrollo.

Dichos pueblos piden con urgencia el respeto a su cultura ancestral, al igual que el derecho a la participación en la vida política y económica de El Salvador. Es un hecho que, históricamente, se ha tenido en poca estima a estos pueblos originarios, y se los discriminó e invisibilizó socialmente durante siglos.

El compromiso ciudadano actual consiste en transmitir a las nuevas generaciones el respeto a los derechos de los pueblos originarios; no discriminar a nadie por sus rasgos, vestimenta, cultura y aceptar la propia cultura ancestral, apoyando a cada persona en su identidad étnica.

\section{Un planteamiento histórico del problema que justifica su importancia}

Los pueblos originarios de El Salvador habían sido relegados al olvido. Prueba de ello es que, apenas hasta el año 2014, el Estado de El Salvador reconoció la existencia de los pueblos indígenas. ${ }^{5}$ Esto, a pesar de que el mismo Estado salvadoreño había aceptado y firmado el compromiso de cumplimiento de la Declaración de las Naciones Unidas sobre los Derechos de los Pueblos Indígenas, y aprobada por la Asamblea General del Órgano Legislativo el 13 de septiembre de 2007. Sin embargo, en la actualidad la mayoría de salvadoreños han perdido la conexión con sus antepasados; y los gobiernos en turno continúan decretando nuevas leyes con vista a un mejor desarrollo económico en El Salvador, con el fin de adaptarse al nuevo mundo globalizado; pero están dejando a un lado las leyes que protegen a los pueblos originarios. Por ejemplo, en la educación cada año agregan nuevos temas con el fin de preparar a los estudiantes frente al futuro del país; una clara evidencia es la adopción como asignatura el idioma inglés, ya que según el nuevo mundo es el idioma universal, sin embargo, se está perdiendo lo más importante: la propia cultura. El sistema educativo está omitiendo cada vez más el aprendizaje de las culturas de los pueblos originarios, de sus ancestros. Esto lleva a que el salvadoreño vaya creciendo con un conocimiento mínimo acerca de sus raíces, de las distintas culturas de estos pueblos, de sus costumbres y de su lengua.
Actualmente, en los pueblos originarios de El Salvador se puede observar cómo su desarrollo se centra en la producción de granos básicos, así como artesanías; sin embargo, la mayoría de personas de estos lugares carecen de estudio básico, puesto que desde pequeños sus padres les han inculcado que vale más aprender un oficio que obtener un título de educación básica, esto permite que el gobierno pueda manejarlas a su antojo, pasando por encima de sus derechos; derechos humanos que los pobladores ignoran. Otro factor de la poca escolaridad es la falta de oportunidades para estudiar, pues o no existe o viven muy retirados de algún centro escolar en su comunidad. A esto se suma, hoy en día, la inseguridad en que vive en el país, en especial los jóvenes.

Además, pocas son las instituciones, públicas y privadas, que tratan la manera de ayudar a estos pueblos originarios, con el fin de evitar que se queden en el olvido y que sean manejados al antojo de los gobernantes y dirigentes. Existen algunos programas de inserción, así como de educación, con el objetivo de que los indígenas puedan defenderse de cualquier situación en su contra. Lastimosamente, pese a estos esfuerzos, aún se necesita un mayor grado de compromiso por parte del Estado para poder ayudar a estos pueblos originarios, y para que en El Salvador se respeten los derechos y se cumpla con las obligaciones de acuerdo con la ley establecida por la Constitución de El Salvador, que los favorecen.

\section{Un marco teórico de investigación}

En El Salvador son muy pocos a los que se les llama indígenas (Dirección General de Estadísticas y Censos, 2007). Algunos miembros de estos grupos humanos, al ser los indígenas grupos socialmente excluidos, aunque tengan un origen genético indígena, niegan su origen para no ser excluidos de las relaciones interpersonales y sociales.

Estos grupos humanos son originarios precisamente porque habitaron estas tierras de El Salvador desde antes de la llegada de los colonos españoles. Por ende, no solo se trata de grupos humanos entre otros, sino de pueblos originarios.

Según Lemus (2014), en un artículo publicado por el periódico digital elfaro.net se opina lo siguiente: 
Con la sangre de los habitantes de estos pueblos originarios se han escrito algunos de los capítulos más tristes de la historia salvadoreña. Su lengua ha enriquecido con numerosos vocablos y topónimos al español que todos hablan cotidianamente. Su sangre corre por las venas de la mayoría de salvadoreños gracias al mestizaje del que fueron víctimas durante la conquista y colonia españolas, que se prolongó con los criollos en tiempos de la República. Sin embargo, la Constitución de la República nunca los reconoció. Es decir, el Estado salvadoreño los ha ignorado desde su fundación. Siempre han sido un pueblo invisible, no porque no se ven, sino porque nunca han contado para el país. Por lo tanto, nunca han tenido derechos.

En la sesión plenaria del jueves 12 de junio del año 2014, en la Asamblea Legislativa de El Salvador, se reformó la Constitución, al modificar el artículo 63, que literalmente dice: "El Salvador reconoce a los Pueblos Indígenas y adoptará políticas a fin de mantener y desarrollar su identidad étnica y cultural, cosmovisión, valores y espiritualidad".

Se ha de hacer hincapié en la formulación del concepto pueblos, ya que se trata del reconocimiento político de diversos grupos humanos con su cultura e identidad particulares. Este reconocimiento los acredita como pueblos con la posibilidad de exigir sus derechos como grupo social. He aquí la dificultad política de la Asamblea Legislativa por este reconocimiento, puesto que con esta reforma el Estado salvadoreño está comprometido con el cumplimiento de los derechos económicos, políticos y culturales de los pueblos originarios de El Salvador.

\section{Sobre la Declaración Universal de Naciones Unidas sobre los Derechos de los Pueblos Indígenas}

Según Naciones Unidas (2007), los pueblos indígenas son iguales a todos los demás pueblos. Y continúa afirmando que todos los pueblos contribuyen a la diversidad y riqueza de las civilizaciones y culturas; y reafirma que los pueblos indígenas deben estar libres de toda forma de discriminación; y manifiesta su preocupación, porque los pueblos indígenas han sufrido injusticias históricas como resultado de la colonización y de haber sido desposeídos de sus tierras, territorios y recursos; además, afirma que existe la necesidad de respetar y promover los derechos de los pueblos indígenas, tanto políticos, económicos como culturales, en especial aquellos derechos referidos a sus tierras, territorios y recursos. Todos estos derechos se basan en los tratados y en los acuerdos reconocidos por los Estados firmantes.

También Naciones Unidas celebra que los pueblos indígenas se estén organizando para promover su desarrollo político, económico, social y cultural; y para poner fin a todas las formas de discriminación y opresión (Naciones Unidas, 2007).

El fin que se persigue es alcanzar, por parte de los pueblos indígenas, el control de sus tierras, territorios y recursos. Esto les permitirá satisfacer sus necesidades y sus aspiraciones.

Estos pueblos indígenas han sufrido la militarización de sus territorios, y en algunos casos la persecución y migración de sus mismas tierras. Es de especial mención el genocidio perpetrado por las fuerzas militares en la masacre del 1932, por parte del Estado salvadoreño (Anderson, 2001).

Naciones Unidas (2007) destaca la necesidad de la paz, el progreso y el desarrollo para los pueblos indígenas; situación de la que han estado excluidos en los países donde habitan. También llama a su organización y a la negociación con los Estados.

Es de vital importancia el reconocimiento de Naciones Unidas del derecho de los pueblos indígenas a la libre determinación de su condición política, económica, social y cultural, porque esto les permite elegir entre los miembros de su pueblo a sus autoridades políticas, y a decidir el tipo de desarrollo económico que han de seguir. Es de notar, en este momento, que apenas se comienza a dar pasos en esta dirección en El Salvador con el reconocimiento de elecciones de alcaldes indígenas en sus propios pueblos (Instituto Salvadoreño de Desarrollo Municipal, 2015). Sin embargo, todavía falta un camino largo por recorrer en las relaciones entre el Estado y los pueblos indígenas salvadoreños.

El derecho a la libre determinación es fundamental para que los pueblos originarios puedan ir recuperando su autonomía y libertad. Esto les permitirá construir sus propias instituciones políticas, jurídicas, económicas, sociales y culturales. Para lastima de todos, el Estado salvadoreño todavía está pendiente de cumplir a cabalidad con este acuerdo y tratado internacional de Naciones Unidas.

Sin embargo, el Estado salvadoreño reconoce que los pueblos indígenas poseen derechos colectivos indispensables para 
su existencia, bienestar y desarrollo. Pero no se trata solo de reconocer, sino de cumplir con tales derechos. Ante todo, no someter a ningún indígena a ningún tipo de discriminación.

De acuerdo con Naciones Unidas (2007), cualquier Estado ha de resarcir los daños provocados en el pasado a todos los pueblos indígenas. En el caso particular de El Salvador, resarcir sus territorios con sus recursos. Menuda tarea la que debe realizar el Estado salvadoreño. Además de la restitución de los bienes culturales, intelectuales, religiosos y espirituales, y, sobre todo, en torno a los derechos políticos y económicos.

\section{Situación general de los pueblos indígenas en El Salvador}

Según Rojas (2017), los pueblos indígenas deben gozar de protección de sus derechos de manera colectiva. Es cierto que estos derechos son reconocidos en la Constitución de la República de El Salvador y el derecho internacional, como la libertad de expresión, de religión, de asociación y de reunión. Sin embargo, todavía el Estado salvadoreño no llega a establecer como una realidad tales derechos.

$\mathrm{Y}$, hoy por hoy, todo comienza por el conocimiento que los funcionarios públicos, las instituciones privadas, los ciudadanos y los propios pueblos indígenas tengan sobre tales derechos promulgados por la ONU.

Los pueblos originarios reconocen problemas en torno a la propiedad de sus antiguas tierras, a su preocupación por la actual situación de pérdida de las lenguas originarias, al impulso de la agricultura, de la educación y de la salud, entre otros desafíos y retos pendientes.

\section{Método}

En la investigación se aplicó la metodología cualitativa, dentro de la cual se realizaron visitas in situ con observación externa y entrevistas no estructuradas para obtener información por parte de los informantes clave.

\section{Informantes claves}

Se seleccionó a distintos informantes clave en las poblaciones de San Martin, Soyapango, Ayutuxtepeque, departamento de San Salvador; Santa Tecla, Lourdes Colón,
Quezaltepeque, departamento de La Libertad; Apastepeque, San Vicente; y El Rosario, La Paz, de El Salvador, para conocer su comprensión en torno al tema de investigación.

\section{Técnicas de investigación}

Se realizaron entrevistas a diferentes informantes clave para conocer su percepción sobre la actual situación de los pueblos originarios y comparar dicha situación con la Declaración de Naciones Unidas sobre los Derechos de Ios Pueblos Indígenas. En específico, conocer testimonios sobre el trato que reciben los indígenas por parte del Estado salvadoreño. Se realizaron varias visitas en distintos municipios para escuchar de viva voz a los informantes clave, quienes proporcionaron datos clave sobre su la actual situación de vida los indígenas.

\section{Instrumentos}

La investigación se centró en el desarrollo de la observación externa y entrevistas semiestructuradas, mediante visitas in situ a los municipios ya antes mencionados; se utilizaron algunas interrogantes referidas a determinar la condición de vida de la población indígena a partir del cumplimiento o no de los derechos de los pueblos originarios, desde la propia percepción y comprensión de los informantes clave.

\section{Resultados}

Según los informantes clave, coinciden en que los pueblos originarios están desapareciendo y constituyen una minoría de la población salvadoreña; y consideran que este tema tiene poca importancia. Afirman que el cumplimiento de los derechos de los pueblos indígenas por parte del Estado les traerá beneficios; que las causas del no cumplimiento radica, primero, en la falta de interés por parte del Estado salvadoreño; segundo, en que los pueblos originarios no tienen un representante legal que defienda sus derechos; y tercero, en la falta de recursos económicos de estos pueblos.

Dentro de las consecuencias, se obtuvo como resultado que se estaba negando la identidad indígena como personas y como pueblos; y esto está llevando a la pérdida de sus tradiciones y costumbres; y lo que más grave, la actual situación está conduciendo al olvido de sus mismos orígenes, constituyendo un peligro real y serio para la continuidad de tales pueblos. 
Como soluciones, proponen una intervención de la sociedad civil y del Estado salvadoreño, en especial de la Asamblea Legislativa, que promueva los valores culturales indígenas y el resarcimiento de las tierras, del empoderamiento político, económico y cultural de dichos pueblos, promoviendo el cumplimiento de sus derechos, establecidos y acordados en la Declaración de Naciones Unidas sobre los Derechos de los Pueblos Indígenas.

\section{Discusión}

Hablar de pérdida y rescate de los derechos económicos, políticos y culturales de los pueblos originarios en El Salvador es una temática relevante. Es un tema que se debe incluir en la agenda de discusión nacional. Por ejemplo, dos puntos de discusión serían la pobreza y la desigualdad social, que afectan a la mayoría de la población indígena. Se trata de personas y comunidades que, a pesar de participar sobre todo en la economía rural, no logran tener los ingresos suficientes para satisfacer sus principales necesidades.

Otro punto evidente es la desigualdad económica entre indígenas y ladinos. Estos pueblos viven sometidos frente al poder de los ladinos para poder mantenerse con vida; $y$ el Gobierno en poco se ocupa para cambiar esta situación y mejorar su calidad de vida Esta situación se evidencia cuando se visitan los pueblos originarios de El Salvador. Temas como la distribución de la tierra, el acceso adecuado a la información, la reforma agraria, la inclusión política y resolución de conflictos civiles, la alta concentración de la propiedad agrícola en manos ladinas en territorios habitados por estos pueblos originarios, la discriminación y la violación de los derechos de los pueblos indígenas, entre otros, es necesario incluirlos dentro de la agenda nacional del Estado salvadoreño.

No poder desarrollarse como las demás personas es una de muchas consecuencias que los indígenas padecen; suelen negar su identidad y sus creencias para adoptar otras nuevas y así acoplarse a las nuevas normativas sociales; olvidan el propio origen y comienzan a transculturizarse. De esta manera evitan la discriminación por practicar la propia cultura, por vivir su propia identidad. Ya los grupos ladinos no respetan los valores, la cosmovisión y las creencias indígenas. Como consecuencia de esta discriminación, se han perdido costumbres y tradiciones propias de la cultura de los pueblos originarios.
Un factor muy importante dentro de la realidad de dichos pueblos que se tiene que discutir es el creciente desinterés por parte de los jóvenes hacia las tradiciones, costumbres y los intereses de los pueblos originarios; simplemente no le dan importancia, les da igual, y prefieren muchas veces seguir tendencias y culturas que no pertenecen al pueblo originario. He aquí una tarea para las autoridades de estos pueblos frente a sus miembros jóvenes.

Por otra parte, el Estado salvadoreño debe realizar las acciones que sean necesarias para el cumplimiento de la Declaración de Naciones Unidas sobre los Derechos de los Pueblos Indígenas.

Según Segovia (2011), en cuanto a las relaciones Estado salvadoreño y pueblos originarios, se deben crear equipos técnicos sobre estos para entablar el diálogo con sus representantes, impulsando equipos multisectoriales y multidisciplinarios para buscar acciones, programas y políticas públicas encaminadas a la mejora en la situación económica, política y cultural de los pueblos indígenas. Y también, "crear un mecanismo presidencial sobre pueblos indígenas, para conversar con las Naciones Unidas, representaciones diplomáticas, organismos de cooperación, comunidad internacional y otros organismos donantes, sobre las posibles formas de cooperación e intercambio de prácticas que beneficien a los Pueblos indígenas de El Salvador" (Segovia, 2011).

Por parte de la sociedad salvadoreña, debe interesarse por conocer la cultura, respetar y estimar las tradiciones de los pueblos originarios; estas acciones harían que en el futuro no sean olvidados completamente y que los indígenas no sean socialmente excluidos y se cumplan sus derechos como individuos y como pueblo.

Tomando en cuenta lo anterior, es necesario promover campañas de información para poder fortalecer la cultura, las costumbres y tradiciones indígenas, y apoyar a los pueblos en sus luchas económicas y políticas. Esto ayudaría incluso a la nación salvadoreña, ya que sería un factor para reducir la violencia social que proviene de la desigualdad económica que padecen los jóvenes de origen indígena. En este punto, juega un papel muy importante el Estado salvadoreño.

Y por parte de los pueblos originarios, han de interesarse más por promover su cultura, sus luchas políticas y económicas, 
y buscar alianzas con distintas y diversas organizaciones sociales, nacionales e internacionales.

Por parte de la sociedad salvadoreña, se necesita el reconocimiento de sus raíces indígenas, incluso en detalles tan pequeños como el reconocer las palabras de origen indígena, que cotidianamente se utilizan, pero que hoy pasan desapercibidas. En conclusión, apoyar a los pueblos originarios es parte de un mejor futuro para El Salvador.

\section{Conclusiones}

Los resultados de la investigación arrojan que el país necesita un cambio urgente respecto a cómo se maneja todo el tema de los derechos de los pueblos indígenas en El Salvador, especialmente por parte del Estado salvadoreño.

En relación con toda la ciudadanía salvadoreña, es necesario tomar conciencia acerca de la propia cultura y de sus raíces. Actualmente el conocimiento acerca de los pueblos originarios y su entorno es muy escaso, y con el paso de los años las nuevas generaciones habrán perdido el interés por conocer las diversas costumbres y culturas de El Salvador. Por ende, es necesario realizar acciones y actividades de promoción sobre la importancia de las culturas indígenas, $\mathrm{y}$ ante todo de la identidad de los pueblos originarios salvadoreños, para que sean conocidos y respetados en sus derechos económicos, políticos y culturales.

Para lograrlo, se requiere de un compromiso de responsabilidad por parte de las distintas instancias públicas y privadas, y de los distintos sectores de la sociedad.

Para dar a una favorable solución a este problema, sería una buena alternativa comenzar a fomentar campañas de información en busca de la creación de diferentes políticas para el adecuado desarrollo de las comunidades indígenas, haciendo uso de las nuevas tecnologías como herramienta para el desarrollo dichas campañas, mediante redes sociales como Facebook y Twitter, entre otras.

Por otra parte, motivar la organización e iniciativa indígenas para que acudan a las instancias necesarias, aquellas que apoyen de una u otra forma la vivencia real de los derechos de los pueblos originarios. Y por último, es necesario que las nuevas generaciones practiquen los valores culturales de sus pueblos originarios, para que no desaparezca la identidad indígena, y de esta forma comiencen a percibirse cambios en cuanto a la manera de ver a los pueblos originarios en El Salvador.

\section{Referencias}

Anderson, T. (2001). El Salvador, 1932: Ios sucesos políticos. San Salvador: Dirección de Publicaciones e Impresos, CONCULTURA.

Asamblea Legislativa. El Salvador. (2014). Constitución de la República de El Salvador. Recuperado de www. asamblea.gob.sv/

Instituto Salvadoreño de Desarrollo Municipal. (2015). Certificación de la Alcaldía del Común de Izalco como alcaldía 163. Recuperado de www.isdem.gob.sv/

Decreto.No.707. Diario Oficial de la Republica de El Salvador, San Salvador, El Salvador, 2014.

Dirección General de Estadísticas y Censos. (2007). Censo de población y vivienda - 2007. Recuperado de www.digestyc.gob.sv/index.../poblacion-y.../censo... poblacion.../ poblacion-censos.html

Lemus, J. (2014). Los pueblos salvadoreños indígenas siempre han existido. Recuperado de www.elfaro.net/.../ Los-pueblos-salvadoreños-indígenas-siempre-hanexistido.htm

Naciones Unidas. (2008). Declaración de las Naciones Unidas sobre los derechos de los pueblos indígenas. Recuperado de http://www.un.org/esa/socdev/ unpfii/documents /DRIPS_es.pdf

Rojas, M. (2017). Cosmovisión indígena de los pueblos de Izalco, Nahuizalco y Santo Domingo de Guzmán, en torno a la construcción histórica de los derechos humanos de los pueblos originarios de El Salvador. Revista Entorno. 64.

Segovia, A. (2011). Respuesta a cuestionario para informe a presentar en la decimo período de sesiones del foro permanente para las cuestiones indígenas, new york, 16 y 17 de mayo 2011. Recuperado de http://www. un.org/esa/socdev/unpfii/documents/Session_10 _ElSalvador.pdf 